\title{
Crescimento relativo e determinação da idade na fase juvenil de Armases angustipes (Dana) (Decapoda, Brachyura, Grapsidae)
}

\author{
Vânia G.L. Kowalczuk ${ }^{2}$ \\ Setuko Masunari ${ }^{3}$
}

\begin{abstract}
Relative growth and age determination of juvenile crab of Armases angustipes (Dana) (Decapoda, Brachyura, Grapsidae). The relative growth of the male chelipod and female abdomen of Armases angustipes (Dana, 1852) was studied in order to determine the carapace size of puberty. Also, the age of juvenile crabs in laboratory was established. A total of 537 males and 557 females were analysed and the transition point between mature and immature stages was determined for both sexes. Males attain maturity at $1.00 \mathrm{~cm}$ carapace width and females at $1.08 \mathrm{~cm}$. The relative growth of female abdomen was more remarkable than that of the male chelipod, although both are positive allometric. It suggests a greater importance of a large abdomen in females than a strong chelipod in males. Juvenile crabs reared from megalopa stage has five developmental stages before reaching sexual differentiation. This occurs in the sixth juvenile stage, when the intermolt stages become longer. The potential equation between carapace width and accumulated duration of juvenile stages is described as $\mathrm{CW}=0,047 \mathrm{D}^{0,508}$.

KEY WORDS. Armases angustipes, crabs, relative growth, age determination
\end{abstract}

Ao longo do processo de crescimento, os animais apresentam mudança na proporção entre certas estruturas, fenômeno denominado crescimento relativo, alométrico ou heterogônico. Os crustáceos, por apresentarem exoesqueleto rígido, são passíveis de medidas precisas e, devido a grandes diferenças no formato associado ao sexo e puberdade, constituem um grupo atrativo para o estudo desse fenômeno (HARTNOLL 1978, 1982).

As mudanças na proporção de crescimento podem ocorrer gradualmente ao longo de uma série de mudas, ou abruptamente em uma única muda (metamorfose), como entre o último estágio larval para o primeiro pós-larval ou do último imaturo para o primeiro maturo. Esta última modalidade é denominada muda da puberdade (PEREZ 1928 apud HARTNOLL 1985).

Padrões de crescimento relativo são responsáveis pelo desenvolvimento de dimorfismo sexual, podendo ser utilizados para predizer estágios de desenvolvimento. Os caracteres sexuais secundários (quela, abdômen e pleópodos) apresentam taxas de crescimento diferenciais antes e após a maturação, podendo apresentar um

1) Contribuição número 1121 do Departamento de Zoologia, Universidade Federal do Paraná.

2) Departamento de Biologia, Universidade Federal de Roraima. Campus do Paricarana, Rodovia BR 174, 69310-270 Boa Vista, Roraima, Brasil.

3) Departamento de Zoologia, Universidade Federal do Paraná. Caixa Postal 19020, 81531-990 Curitiba, Paraná, Brasil. 
significado adaptativo em termos de função na reprodução da espécie, como movimentos de corte, agonísticos ou na incubação dos ovos (HARTNOLL 1974, 1978, 1982, 1985; VANNINI \& GHERARDI 1988).

O reconhecimento da muda da puberdade é um subsídio para uma análise da estratégia de crescimento e de reprodução dentro de uma espécie (HARTNOLL 1985).

O crescimento na fase juvenil é pouco conhecido para os braquiúros, devido à dificuldade de identificar exemplares juvenis coletados em campo e à baixa taxa de sobrevivência de larvas cultivadas em laboratório até a fase juvenil (NEGREIROSFRANSOZO \& FRANSOZO 1991).

O aspecto ecológico no estudo da fauna de Decapoda do litoral paranaense é recente, especialmente de substratos rochosos. MELo et al. (1989) estabeleceram uma lista preliminar desses animais nos diversos ambientes litorâneos paranaenses; MASUNARI et al. (1998) descreveram a flutuação anual da densidade das populações de Decapoda do substrato rochoso da Ilha do Farol, Matinhos, Paraná e analisaram o padrão de reprodução das mesmas, e MASUNARI \& DUBIASKI-SILVA (1998) descreveram a distribuição espacial de densidade dessas mesmas populações. KOWALCZUK \& MASUNARI (2000) estudaram alguns aspectos da população de Armases angustipes (Dana, 1852) da Ilha do Farol, Paraná, tais como densidade, proporção de sexos, período de atividade e composição de tamanho ao longo do ano de 1991.

O presente trabalho tem como objetivo investigar dois aspectos do crescimento em A. angustipes: verificar o tamanho da maturação através do crescimento relativo entre a quela e $o$ abdômen e a largura da carapaça em indivíduos coletados em campo e determinar a idade através do tamanho de indivíduos juvenis criados em laboratório.

\section{MATERIAL E MÉTODOS}

O presente estudo foi realizado na porção oeste da Ilha do Farol (2551'S, $48^{\circ} 32^{\prime} \mathrm{W}$ ), na faixa supralitoral do substrato rochoso (ver descrição da área e mapa em MASUNARI et al. 1998).

As coletas foram realizadas mensalmente de janeiro a dezembro de 1991, nos períodos noturno e diurno, sempre durante a baixa-mar. A metodologia de coleta está descrita detalhadamente em KowALCZUK \& MASUNARI (2000). De um total de 1139 caranguejos coletados, 537 machos e 557 fêmeas tiveram os seguintes dados merísticos tomados através de um paquímetro com precisão de $0,05 \mathrm{~mm}$ : largura da carapaça (LC) de todos os exemplares, comprimento das quelas (CQ) dos machos e largura do abdômen (LA) das fêmeas.

Os pontos empíricos referentes à relação entre a largura da carapaça e o comprimento da quela para machos e largura da carapaça e largura do abdômen para fêmeas foram plotados com o auxílio do programa Excel, para visualizar uma possível quebra no gráfico de dispersão dos pontos. Com o programa estatístico Regrans (PEZZUTO 1993), foi calculada a equação de regressão para todos os pontos empíricos e logaritmizados, detectado o ponto de inflexão e calculadas as equações dos pontos à esquerda e direita daquele; através deste programa, ainda foi feita 
análise de covariância para verificar a significância da declividade (b) calculada pelas regressões parciais.

No estudo da determinação da idade, 180 larvas foram obtidas em laboratório a partir de uma fêmea ovígera coletada em campo, as quais foram criadas individualmente em recipientes numerados de vidro de $25 \mathrm{ml}$. Elas foram alimentadas com náuplios de Artemia sp. e a água do mar filtrada foi renovada diariamente. Ao passar para a fase juvenil, os caranguejos foram transportados para recipientes de vidros de $80 \mathrm{ml}$ com seixos no fundo, cuja água foi trocada diariamente. A partir do quarto estágio de juvenil, os animais foram transferidos para recipientes de $300 \mathrm{ml}$ com água do mar filtrada e aerada constantemente. Quanto à alimentação, nos estágios de juvenil foram acrescentados pequenos pedaços de camarão na dieta. Diariamente foram anotadas mortes e ecdises, e indivíduos mortos e exúvias foram conservadas em álcool a 70\% glicerinado. Os juvenis foram medidos sob microscópio estereoscópico com ocular graduada.

Foram calculadas as médias da largura da carapaça e da duração para cada estágio juvenil e o coeficiente de variação. Com o auxílio do programa Excel, foram plotadas as médias referentes à largura da carapaça (LC) e a duração de cada estágio dos juvenis (D). O gráfico de dispersão das médias sugeriu uma relação curvilínea, determinada pela expressão: $\mathrm{LC}=\mathrm{AD}^{\mathrm{b}}$.

\section{RESULTADOS}

\section{Crescimento relativo da quela em machos e abdômen em fêmeas}

A figura 1 mostra a dispersão dos pontos das relações entre o comprimento da quela e a largura da carapaça nos machos e a figura 2, a dispersão entre a largura do abdômen e a largura da carapaça nas fêmeas. Em ambas as relações, o modelo potencial forneceu melhor ajuste nos pontos, sendo detectado o ponto de inflexão na relação nos machos em $1,00 \mathrm{~cm}$ de largura de carapaça e nas fềmeas em $1,08 \mathrm{~cm}$ de largura de carapaça.

A relação mostrou ser válida para os machos, através das seguintes expressões:

- para todos os machos $(n=537 ; r=0,982): C Q=0,532 L^{1,218}$

- para machos com largura de carapaça menor que $1,00 \mathrm{~cm}(n=344 ; \mathrm{r}=0,978)$ : $\mathrm{CQ}=0,512 \mathrm{LC}^{1,131}$

- para machos com largura de carapaça maior que $1,00 \mathrm{~cm}(n=193 ; r=0,980)$ : CQ $=0,517 \mathrm{LC}^{1,430}$

O coeficiente angular (coeficiente de crescimento) foi alométrico positivo para todas as equações (total e parciais), sendo que o ponto de inflexão é validado pelo $\mathrm{F}$ calculado da análise de covariância das declividades das retas parciais $(\mathrm{F}=$ $94,902)$. Portanto o coeficiente de crescimento é maior nos machos das classes superiores a $1,00 \mathrm{~cm}(1,430)$, indicando que, nestas classes a quela tem um crescimento proporcionalmente maior ao restante do corpo do que nos machos com menos de $1,00 \mathrm{~cm}$ de largura da carapaça.

A relação da largura da carapaça e largura do abdômen para as fêmeas mostrou uma relação potencial com as seguintes expressões: 
- para todas as fêmeas $(n=557 ; r=0,983): L A=0,555 \mathrm{LC}^{1,479}$;

- fêmeas com largura de carapaça menor que $1,08 \mathrm{~cm}(\mathrm{n}=427 ; \mathrm{r}=0,978)$ : $\mathrm{LA}=$ $0,523 \mathrm{LC}^{1,351}$

- fêmeas com largura da carapaça maior que $1,08 \mathrm{~cm}(\mathrm{n}=130 ; \mathrm{r}=0,946)$ : $\mathrm{LA}=$ $0,559 \mathrm{LC}^{1,691}$.

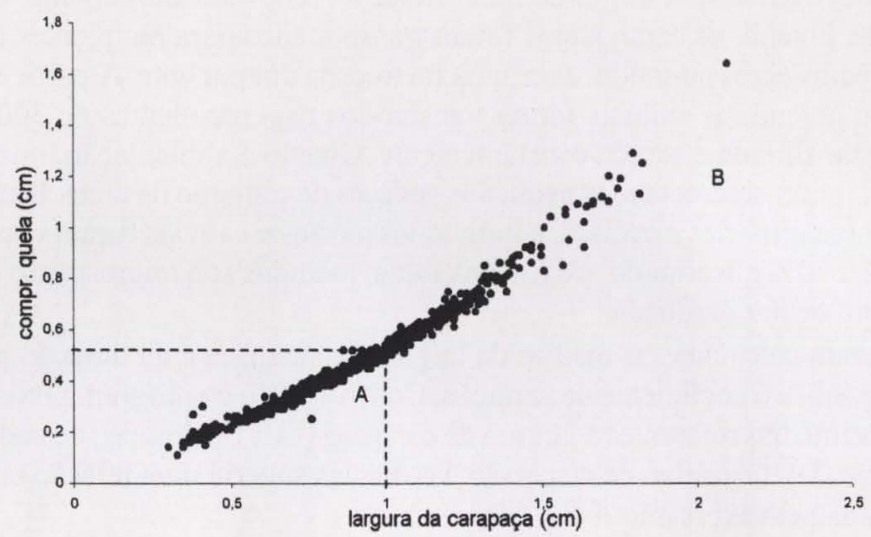

Fig. 1. Armases angustipes. Dispersão dos pontos empíricos da relação entre o comprimento da quela (CQ) e a largura da carapaça ( $L C$ ) dos machos. (A) Pontos menores que $1,00 \mathrm{~cm}$, $C Q=0,512 L^{1,131} ;(B)$ pontos maiores que $1,00 \mathrm{~cm}, C Q=0,517 \mathrm{LC}^{1,430}$.

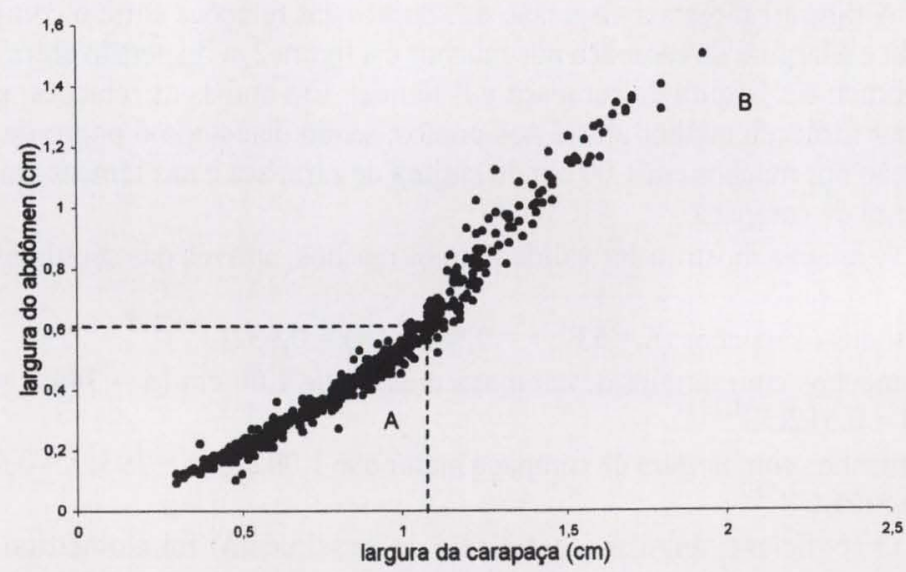

Fig. 2. Armases angustipes. Dispersão dos pontos empíricos da relação entre a largura do abdômen (LA) e a largura da carapaça (LC) das fêmeas. (A) Pontos menores que $1,08 \mathrm{~cm}$, $L A=0,523 L C^{1,351} ;(B)$ pontos maiores que $1,08 \mathrm{~cm}, L A=0,559 L C^{1,691}$.

O coeficiente angular (coeficiente de crescimento) foi alométrico positivo para todas as equações (total e parciais), sendo que o ponto de inflexão é validado pelo $\mathrm{F}$ calculado da análise de covariância das declividades das retas parciais ( $\mathrm{F}=$ $35,999)$. Portanto o coeficiente de crescimento é maior nas fêmeas de tamanho 
superior a 1,08 cm (1,691), indicando que, nestas classes o abdômen tem um crescimento proporcionalmente maior ao restante do corpo do que nas fêmeas com menos de $1,08 \mathrm{~cm}$ de largura da carapaça.

Indivíduos com as dimensões próximas ao ponto de inflexão e/ou maiores são mais freqüentes nos meses de primavera/verão, quando coincide com o período reprodutivo da espécie (KOWALCZUK \& MASUNARI 2000).

\section{Determinação da idade dos juvenis criados em laboratório}

O tamanho dos indivíduos e a duração dos estágios dos caranguejos criados em laboratório estão na tabela I. Dos sete estágios juvenis obtidos, o sexto e o sétimo já estão sexualmente diferenciados. A duração média dos estágios variou de 4,90 dias (juvenil I) aumentando gradativamente até 23,43 dias (juvenil VII), enquanto o percentual de crescimento variou de $16,22 \%$ (juvenil VII) a $35,71 \%$ (juvenil III), com uma tendência à diminuição deste valor nos estágios mais adiantados. A figura 3 mostra a dispersão das médias da relação entre a largura da carapaça e a duração de cada estágio juvenil, e ficou determinada pela seguinte expressão $(r=0,998): L C=0,047 D^{0,508}$.

Tabela I. Armases angustipes. Média e coeficiente de variação da largura da carapaça $(\mathrm{cm})$ e da duração (dias) de cada estágio juvenil e porcentagem de crescimento da média da largura da carapaça.

\begin{tabular}{lcccccc}
\hline \multirow{2}{*}{ Estágios } & \multicolumn{2}{c}{ Largura da carapaça $(\mathrm{cm})$} & & \multicolumn{2}{c}{ Duraçăo (dias) } & Crescimento (\%) \\
\cline { 2 - 3 } & Média & Variaçăo & & Média & Variação & \\
\hline Juvenill & 0,11 & 10,19 & & 4,90 & 33,14 & - \\
Juvenil II & 0,14 & 8,78 & & 4,50 & 13,54 & 27,27 \\
Juvenil III & 0,19 & 8,39 & & 6,88 & 41,83 & 35,71 \\
JuvenillV & 0,24 & 8,46 & & 10,18 & 46,32 & 26,31 \\
Juvenil V & 0,30 & 2,18 & & 13,27 & 29,88 & 25,00 \\
Juvenil VI & 0,37 & 8,33 & & 14,60 & 35,58 & 23,33 \\
Juvenil VII & 0,43 & 8,61 & & 23,43 & 30,72 & 16,22 \\
\hline
\end{tabular}

A figura 4 representa a curva de crescimento dos indivíduos criados em laboratório. Observa-se um aumento na duração dos estágios mais adiantados. Em contraste, a porcentagem de crescimento da média da largura da carapaça em relação ao estágio anterior tende a decrescer. Individuos juvenis de A. angustipes são capturados em campo somente após o estágio de juvenil III (KowALCZUK \& MASUNARI 2000).

\section{DISCUSSÃO}

HARTNOLL (1974) comparando o crescimento dos caracteres sexuais secundários de 26 espécies de Brachyura, propõe que, embora haja grande variação nas taxas de crescimento de espécie para espécie, ele segue o mesmo padrão. Nos machos, a quela exibe uma alometria positiva considerável antes da puberdade, um grande aumento de tamanho na puberdade e um nível de alometria mais alto após esta, ao passo que, nas fêmeas, a alometria positiva é baixa e nenhuma mudança marcante ocorre após a puberdade. O abdômen do macho é mais ou menos isométrico, com um pequeno aumento na puberdade, enquanto nas fêmeas há alometria fortemente positiva antes da puberdade, um aumento marcante nesta e, uma alometria positiva reduzida da puberdade em diante. 


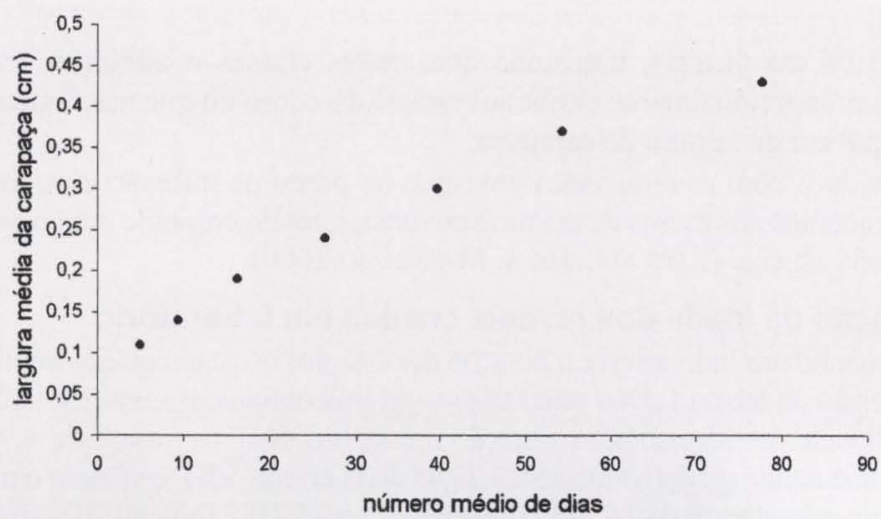

Fig. 3. Armases angustipes. Dispersão das média da largura da carapaça e da duração média acumulada de cada estágio juvenil.

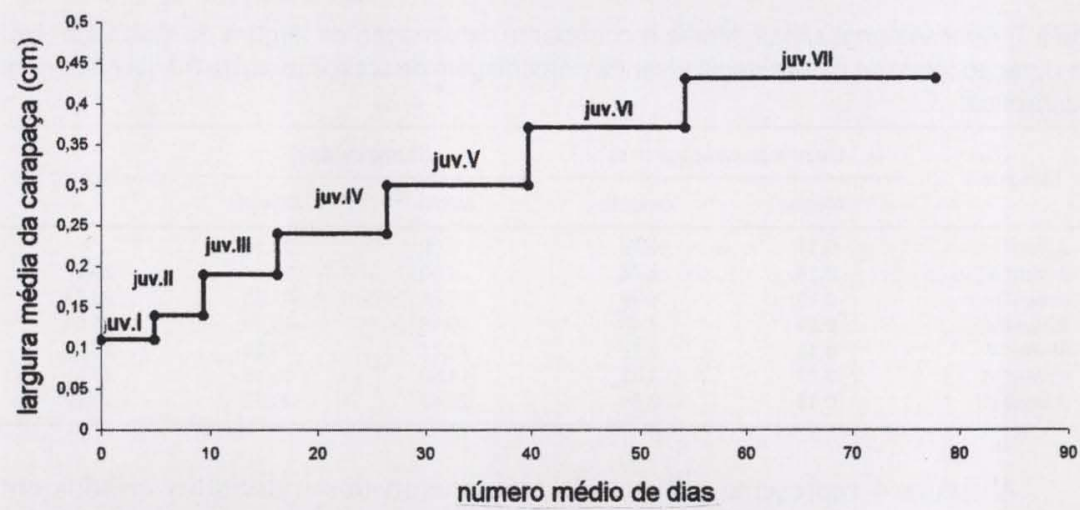

Fig. 4. Armases angustipes. Curva de crescimento construída pela interação dos dados de crescimento das mudas e duração do período entre mudas.

Armases angustipes da Ilha do Farol sempre apresenta alometria positiva nas relações estudadas, mas com aumento na taxa de crescimento da quela do macho e do abdômen da fêmea após a puberdade. O nível de alometria no crescimento da quela dos machos $(1,13$ e 1,43) é menor do que a média de todas as espécies listadas em HARTNOLL (1974), 1,26 antes da puberdade e 1,53 após a puberdade, estando próxima ao de Inachus phalangium (Fabricius), com 1,17 antes e 1,43 após a puberdade. Por outro lado, o nível de alometria no crescimento do abdômen das fêmeas $(1,35$ e 1,69$)$ é superior à média das espécies listadas pelo mesmo autor, especialmente após a puberdade, 1,34 antes da puberdade e 1,16 após a puberdade e não segue o padrão de diminuição no nível de alometria citado anteriormente. Das espécies listadas em HARTNOLL (1974); PINHEIRO \& FRANSOZO (1993) e GóEZ \& FRANSOZO (1997), sete apresentam um nível de alometria maior no crescimento do abdômen das fêmeas maduras e 17, um nível de alometria menor, sendo que de todas as espécies citadas nos três trabalhos, Eriphia smithi Mac Leay, 1838 é a única a 
apresentar alometria após a puberdade maior que a espécie em estudo $(1,715)$ (GóEZ \& Fransozo 1997) e Portunus pelagicus (Linnaeus, 1758) é a que apresentou alometria mais semelhante a Armases angustipes com 1,21 antes e 1,52 após a puberdade HARTNOLL (1974). Estes resultados indicam que, o tamanho da quela do macho nessa espécie não apresenta função tão importante para reprodução ou comportamento agonístico. A forte dominância numérica de $A$. angustipes registrada por MASUNARI \& DUBIASKI-SILVA (1998) indica ser uma população sem muitos competidores na faixa do supralitoral, o que corrobora a hipótese da quela não ser importante no comportamento agonístico inter-específico. Em contraste, o abdômen bem desenvolvido para a fêmea adulta é fundamental no suporte dos ovos, e por viver a maior parte da vida em ambiente aéreo, necessitaria de uma superfície interna maior de abdômen para manter a umidade.

Embora o tamanho estimado de maturação para esta espécie tenha sido 1,00 $\mathrm{cm}$ de largura de carapaça para os machos e $1,08 \mathrm{~cm}$ para as fêmeas, ressalta-se que este resultado fornece algum indício sobre o tamanho de maturidade sexual, mas apenas o exame do sistema reprodutivo e a utilização de taxas de produção permitem inferir mais sobre o significado do tamanho no estabelecimento da maturidade sexual (GóES \& FRANSOZO 1997); e, como analisado por PINHEIRO \& FRANSOZO (1998), apesar da forte associação entre o desenvolvimento de caracteres sexuais secundários e a maturidade fisiológica, em muitas espécies de Portunidae, estes eventos não são sincronizados.

HARTNOLL (1982) reporta algumas diferenças para os resultados de crescimento de caranguejos em laboratório, tais como um incremento menor nas mudas e uma duração maior entre as ecdises destes do que nos indivíduos na natureza.

A diferenciação sexual ocorreu, no presente trabalho, no sexto estágio juvenil de $A$. angustipes, quando os caranguejos medem, em média, $0,37 \mathrm{~cm}$ de largura de carapaça. FRANSOZO (1986) aponta a diferenciação somente no décimo primeiro estágio em Sesarma rectum Randall, 1840, uma espécie de Grapsidae, quando esta mede, em média, $0,41 \mathrm{~cm}$ de largura da carapaça. Embora a diferenciação sexual nesta espécie ocorra após cinco ecdises a mais do que $A$. angustipes, a largura da carapaça, nesta ocasião, tem medidas próximas em ambas as espécies. Os presentes dados de diferenciação sexual são corroborados pelos resultados de KowALCZUK \& MASUNARI (2000) que obtiveram indivíduos sexualmente diferenciados somente a partir da classe $0,30-0,39 \mathrm{~cm}$ de largura de carapaça.

A redução na porcentagem de incremento a partir do terceiro estágio juvenil concorda com a proposição de HARTNOLL (1982) para os decápodos, mas não concorda com os dados apresentados para as três espécies de braquiúros estudadas por NEGREIROS-FRANSOZO \& FRANSOZO (1991), que não apresentam padrão de acréscimo ou decréscimo ao longo dos estágios de juvenis.

Observando o gráfico de regressão de $S$. rectum em NEGREIROS-FRANSOZO \& FRANSOZO (1991), identifica-se um aumento na duração entre as mudas, a partir do décimo e décimo primeiro estágio, quando os caranguejos se tornam sexualmente diferenciados. Estes dados corroboram os resultados obtidos para A. angustipes, no que concerne ao aumento da duração entre as mudas a partir da diferenciação sexual, fato que aconteceu no quinto ou sexto estágio na referida espécie. 
As observações do presente trabalho permitem concluir que $A$. angustipes segue o padrão geral de crescimento juvenil dos Brachyura estabelecido por HARTNOLL (1982), porém, a espécie guarda características intrínsecas quando comparada com outras da mesma família.

\begin{abstract}
AGRADECIMENTOS. Ao Prof. Dr. Gustavo Augusto Schmidt de Melo, do Museu de Zologia da Universidade de São Paulo, pela identificação da espécie em estudo. Ao Prof. M.Sc. Paulo Pezzuto, da Fundação Universidade do Vale do Itajai (Itajaí, Santa Catarina), pela concessão no uso do programa Regrans de sua autoria. Ao Conselho Nacional de Desenvolvimento Científico e Tecnológico ( $\mathrm{CNPq})$, que através do Curso de Pós-Graduação em Ciências Biológicas-Zoologia da Universidade Federal do Paraná concedeu uma bolsa de mestrado à primeira autora para o desenvolvimento do presente trabalho.
\end{abstract}

\title{
REFERÊNCIAS BIBLIOGRÁFICAS
}

Fransozo, A. 1986. Desenvolvimento dos estágios juvenis de Sesarma (Holometopus) rectum Randall, 1840 (Decapoda, Grapsidae) obtidos em laboratório. Naturalia 11/12: 77-87.

GóEs, J.M. DE \& A. FrANSOZO. 1997. Relative growth of Eriphia gonagra (Fabricius, 1781) (Crustacea, Decapoda, Xanthidae) in Ubatuba, State of São Paulo, Brazil. Nauplius 5 (2): 85-98.

HARTNOLL, R.G. 1974. Variation in growth patterns between some secondary sexual characters in crabs (Decapoda: Brachyura). Crustaceana 27: 131-136.

- 1978. The determination of relative growth in Crustacea. Crustaceana 34 (3): 281-293.

1982. Growth, p.111-196. In: L.G. ABELE (Ed.). The Biology of Crustacea. 2. Embriology, morphology and genetics. New York, Academic Press New York, 440p.

. 1985. Growth, sexual maturity and reproductive output. Crustacean Issues 3: 101-128.

KoWALCZUK, V.G.L. \& S. MASUNARI. 2000. Estrutura populacional de Armases angustipes (Dana, 1852) (Decapoda, Brachyura, Grapsidae) da Ilha do Farol, Matinhos, Paraná. Revta bras. Zool. 17 (1): $1-16$.

Masunar1, S.; E. Oliveira \& V.G.L. Kowalczuk. 1998. Crustacea Decapoda da praia rochosa da Ilha do Farol, Matinhos, Paraná. I. Distribuição temporal de densidade das populações. Revta bras. Zool. 15 (1): 219-239.

MAsunARI, S. \& J. Dubiaski-Silva. 1998. Crustacea Decapoda da praia rochosa da Itha do Farol, Matinhos, Paraná. II. Distribuição espacial de densidade das populações. Revta bras. Zool. 15 (3): 643-664.

Melo, G.A.S.; V.G. Veloso \& M.C. Oliveira.1989. A fauna de Brachyura (Crustacea: Decapoda) do litoral do Estado do Paraná. Lista preliminar. Nerítica 4 (1/2): 1-31.

Negreiros-Fransozo, M.L. \& A. Fransozo. 1991. Growth and age determination of three juvenile crab species (Crustacea, Decapoda, Brachyura). Pap. Avuls Zool., São Paulo, 37 (18): 277-283.

PEzzUTO, P.R. 1993. Regrans: a "basic" program for an extensive analysis of relative growth. Atlântica 15: 93-105.

Pinheiro, M.A.A. \& A. Fransozo. 1993. Relative growth of the speckled swimming crab Arenaeus cribarius (Lamarck, 1818) (Brachyura, Portunidae), near Ubatuba, State of São Paulo, Brazil. Crustaceana 65 (3): 377-388.

. 1998. Sexual maturity of the speckled swimming crab Arenaeus cribarius (Lamarck, 1818) (Decapoda, Brachyura, Portunidae), in the Ubatuba littoral, São Paulo State, Brazil. Crustaceana 71 (4): 434-452.

VANINNI, M. \& F.GERHARDI. 1988. Studies on the pebble crab, Eriphia snithi Mac Leay 1838 (Xanthidae: Menippidae): pattern of relative growth and population structure. Trop. Zoology 1 (2): 203-216.

Recebido em 04.III.1999; aceito em 17.1.2000. 